\title{
Determinants of primary healthcare patients' dissatisfaction with the quality of provided medical services
}

\author{
Agnieszka Strzelecka ${ }^{1, A-B, D, F \oplus}$, Michał Stachura ${ }^{2, B-C, F} \oplus$, Tomasz Wójcik ${ }^{1, B-C, F \oplus}$, Marta Kordyzon ${ }^{1, A-C, F \oplus}$, \\ Jarosław Piotr Chmielewski ${ }^{3, A, C, F \oplus}$, Magdalena Florek-Łuszczki ${ }^{4, D-F}$, Grażyna Nowak-Starz ${ }^{1, C, E-F} \oplus$ \\ ${ }^{1}$ Collegium Medicum, Institute of Health Sciences, Jan Kochanowski University, Kielce, Poland \\ ${ }^{2}$ Department of Economics and Finance, Faculty of Law and Social Sciences, Jan Kochanowski University, Kielce, Poland \\ ${ }^{3}$ College of Rehabilitation, Warsaw, Poland \\ ${ }^{4}$ Institute of Rural Health, Lublin, Poland \\ A - Research concept and design, B - Collection and/or assembly of data, C - Data analysis and interpretation, \\ $D$ - Writing the article, E - Critical revision of the article, F- Final approval of article
}

Strzelecka A, Stachura M, Wójcik T, Kordyzon M, Chmielewski JP, Florek-Łuszczki M, Nowak-Starz G. Determinants of primary healthcare patients' dissatisfaction with the quality of provided medical services. Ann Agric Environ Med. 2021; 28(1): 142-148. doi: 10.26444/aaem/132783

\begin{abstract}
Introduction. The quality of medical services and health care are complex problems with a number of various definitions, conceptual approaches, measurement tools and techniques. The most important influence on quality in primary health care has the (immaterial) human factor, the relationship between patient and doctor, medical personnel and the primary health care institution, and the skill to use new technologies to improve quality in health care.

Objective. The aim of the study is to discover the determinants of primary health care patients' dissatisfaction with the quality of medical services.

Materials and method. Patients with medical appointments on the day of the survey and gave their consent to participate were included in the study. A total of 901 patients of primary health care institutions [591 (65.59\%) women and 310 (34.41\%) men] in the Świętokrzyskie Province took part. The diagnostic poll method based on a questionnaire examining the patients' satisfaction with the quality of health services was used. Logistic regression identified the determinants of dissatisfaction of the patients.

Results. The determinants that mostly affected the patients' dissatisfaction with medical services were: rudeness of the doctor $(p=0.0001)$, rudeness of the rest of medical staff $(p=0.0001)$, non-comprehensibility of information about health by the patient $(p=0.004)$, no clear identification of the patient in the health care system $(p=0.01)$, and difficult access to information regarding the health condition (medical documentation) $(p=0.018)$.

Conclusions. Primary health care patients who participated in the study pointed to the attitude of the doctor towards a patient during a visit, and the attitude of the remaining medical personnel among the determinants of dissatisfaction with medical services.
\end{abstract}

\section{Key words}

primary health care, quality of medical services, patient, e-Health

\section{INTRODUCTION}

Over forty years ago, the World Health Organisation (WHO) defined Primary Health Care (PHC) for the first time as healthcare which, with the use of practically, scientifically and socially acceptable methods and technologies, is affordable to both developed and developing countries [1]. The 1978 declaration contains the primary definition and description of PHC services, such as health promotion, prophylaxis, treatment and rehabilitation [2]. In common use, the term 'primary health care' can have both a social and a clinical dimension $[3,4]$. The definition proposed by the WHO indicates the social character of primary health care which is commonly accessible to the people, families, or whole societies who take an active part in it [3]. The clinical perspective defines $\mathrm{PHC}$ as the starting point of contact between medical personnel and the people in need

Address for correspondence: Magdalena Florek-Łuszczki, Institute of Rural Heath, Jaczewskiego 2, 20-090, Lublin, Poland

E-mail: magdalena.florek@wp.pl

Received: 08.11.2020; accepted: 22.01.2021; first published: 19.02.2021 of help [1-3]. The organisational idea of primary health care shows the place, time, and management of work of the first level of healthcare, and places it within a network of care facilities [5]. The comprehensiveness, continuity and availability of the described services make it an important element of healthcare concentrated on the promotion of health, prophylaxis, and treatment of diseases, and gives the possibility for an effective reaction to the new challenges and health risks which appear [6]. Furthermore, PHC based on rules of equality in the accessibility to medical services, increases the chances of fulfilling the goals of a balanced development and of universal health coverage $[7,8]$. By increasing common access to medical services, primary health care aims at preventing the phenomenon of inequality in health, and at the same time decreasing the deficiencies and inequalities in a society's health condition [9]. In the 2008 WHO report, PHC was defined anew as a type of care concentrated on the needs of people and responsible for the identification of a population, and bringing people nearer to a comprehensive healthcare service [10]. PHC reforms focus on the most important aspects of healthcare, such as 
accessibility and equality, people's needs and expectations in relation to care, social welfare, and proper leadership in the domain of health [11].

The quality of medical services and the quality of health care are complex problems with a number of various definitions, conceptual approaches, and measurement tools and techniques associated with them [12]. Different ways of defining quality by managers, medical personnel or patients, introduce further differences into the approach to and standardization of the issues related to the quality of care $[12,13,14]$. Donebedien defined quality as a type of care in which the primary goal is the good of the patient, along with their expectations, with consideration of the gains and losses found at each stage of treatment [15]. According to that way of thinking, the sum of the three dimensions of quality (structure, process, and result) and their harmonious interplay, form the final quality of service [16]. The final quality of health services is formed by technical quality (standards and procedures) and functional quality (the manner of implementing and adjusting the service to the needs of the client) [17].

Unique and related definitions of quality have been proposed by the World Health Organisation and by the Institute of Medicine (IOM). They define quality as a process of strategic choices and implementations of medical actions based on sound medical knowledge, intended to increase benefits and minimise the losses in health $[12,15]$. According to quality management systems (ISO), quality is the degree to which a set of inherent properties is able to fulfil the needs of patients [12], and modern ideas of quality refer to the comparison of the degree of fulfilment of their needs. In that, they allow one to understand quality as the difference between the expectations and the perception of a medical service $[13,18]$. The interpretation of quality as the ability to fulfil the needs of patients was included in the definition of quality adopted by the American National Standards Institute (ANSI) and the American Society for Quality (ASQ) [19]. The quality of medical services is determined not only by the needs and expectations of the patients, but also by the interpersonal relations formed at healthcare institutions [20].

The Act on Primary Health Care indicates the possibility of using e-Health in order to improve the quality of medical services [21]. The implementation of modern information and communication technologies increases the possibilities of improving the quality of medical services in healthcare institutions. Using e-Health solutions can lead to increased patient satisfaction, and also influence building good relations between the participants of the healthcare system [22]. According to WHO definition, the term e-Health is related to the usage of any information and communication technologies in order to increase the quality and safety of health care. In its scope, e-Health includes actions of prevention, education, diagnosis, therapy and medical care, regardless of the time and place of providing the service [23]. The e-Health system uses Information Technologies (ICTs) in service processes, but also in processes which change the organisation of healthcare systems in order to improve the health of the population, and the effectiveness and capacity of providing health services [24,25]. e-Health solutions can lead to an improvement in the quality of medical services through continuous monitoring of patients' health parameters $[26,27]$.

It is primarily the (immaterial) human factor, the relationship between patient and doctor, medical personnel and primary health care institution, and the skill to use new technologies in order to improve the quality in health care, that have the foremost influence on quality in primary health care.

\section{OBJECTIVE}

The aim of the study was to discover the determinants of primary health care patients' dissatisfaction with the quality of medical services.

\section{MATERIALS AND METHOD}

The research was planned as a representative regarding the Świętokrzyskie Province. Stratified sampling without repetition was used on patients from 20 health care facilities. Based on the data from the National Health Fund, a list of all institutions in the Świętokrzyskie Province which provided health services within primary health care, was made, as of March 2018. The ultimate study was preceded by an initial study which gave not only an initial assessment of the actual state, but also served to establish the minimal size of the sample needed to carry out the ultimate study. This was carried out at 20 primary health care institutions (10 public and 10 non-public). The directors of all the randomly chosen institutions gave written consent to carry out the study at a given primary health care facility.

The diagnostic poll method was used in the research. A questionnaire for gathering information on the patients' satisfaction with the quality of health services provided by the primary health care institutions was used. This was designed at the Department of Epidemiology and Health Promotion of the School of Public Health of the Centre of Postgraduate Medical Education (CPME), in collaboration with representatives of the Warsaw Centre for Public Health and the Department of Health Promotion and Postgraduate Education of the National Institute of Hygiene in a 2005 research project completed within the CPME (Grant No. 5012-4-01-34/05). Consent was given to use this questionnaire (dr n. med. Piotr Supranowicz, the National Institute of Public Health - National Institute of Hygiene, Warsaw and the Public Health Department in Warsaw, 2011)

The second tool was a survey poll of own design which was elaborated and verified as part of statutory research No. 615554 entitled 'The use of e-Health strategy instruments in primary health care facilities in the Swiętokrzyskie Voivodeship'. The research was given a positive opinion by the Bioethical Commission of the Faculty of Medicine and Health Sciences of Jan Kochanowski University in Kielce, Poland (No. 15/2017).

The questions in the surveys related to the assessment of the quality of provided health care concerned the following: a general assessment of the services provided by the clinic, the conditions of health care at the clinic (the possibility to freely choose a GP, the means of signing up to a GP, waiting time for a GP visit, and the waiting time outside the doctor's office, being admitted to a GP in an emergency, the clinic being provided with the necessary tools and equipment, and the availability of information), an assessment of the course of treatment (the type of visit, the patient's consent to a given treatment or diagnostic tests where the doctor took into 
consideration the patient's financial situation, assessment of house visits, comprehensibility of information regarding health), assessment of the clinic's personnel (the doctor's attitude towards the patient, the way the doctor greeted the patient, course of the visit, attitude of the remaining personnel towards the patient), and a comparison of the quality of services received at the primary health care clinic to private offices (doctor's politeness, accessibility to services, and the quality of service). Questions regarding the use of e-Health tools at the primary health care institutions included the most important areas of e-Health usage in the healthcare system, and verified which solutions in the discussed area functioned (were used) in the primary health care institution under study, according to the patients' opinions (knowledge).

Patients of legal age who had a medical appointment on the day of the survey at a given institution, and who gave their consent to participate in the study, were included in the research. A total of 901 patients of primary health care institutions in the Swiętokrzyskie Province took part in the study - 310 (34.41\%) men and 591 (65.59\%) women. In both groups, the majority were from a city $(57.10 \%$ and $52.45 \%)$. Men most frequently indicated a basic/vocational education (38.06\%), while women indicated higher and highschool (31.90\% each). In both genders the highest number of participants we are professionally active $(62.26 \%$ and $58.38 \%)$, and were in a relationship (60.65\% vs $69.04 \%$ ) (Tab. 1$)$.

Table 1. Characteristics of the sample

\begin{tabular}{|c|c|c|}
\hline Variables & $\begin{array}{c}\text { Male } \\
(n=310)\end{array}$ & $\begin{array}{l}\text { Female } \\
(n=591)\end{array}$ \\
\hline Age $(M, S D)$ & $50.01(18.49)$ & $45.32(16.61)$ \\
\hline \multicolumn{3}{|l|}{ Place of residence $(n, \%)$} \\
\hline City & $177(57.10)$ & $310(52.45)$ \\
\hline Country & $133(42.90)$ & $281(47.55)$ \\
\hline \multicolumn{3}{|l|}{ Education (n, \%) } \\
\hline Higher & $71(22.90)$ & $189(31.90)$ \\
\hline Higher vocational (BA) & $24(7.74)$ & $51(8.63)$ \\
\hline High-school & 79 (25.48) & $189(31.98)$ \\
\hline Basic/vocational & $118(38.06)$ & $110(18.61)$ \\
\hline Primary school & $18(5.81)$ & $52(8.80)$ \\
\hline \multicolumn{3}{|l|}{ Professional activity (n, \%) } \\
\hline Student & $16(5.16)$ & $45(7.61)$ \\
\hline Working & $193(62.26)$ & $345(58.38)$ \\
\hline Retired & $74(23.87)$ & $92(15.57)$ \\
\hline Pensioner & $25(8.06)$ & $25(4.23)$ \\
\hline Unemployed & $2(0.65)$ & $84(14.21)$ \\
\hline \multicolumn{3}{|l|}{ Marital status (n, \%) } \\
\hline Single & $61(19.68)$ & $90(15.23)$ \\
\hline Widower/Spinster & $61(19.68)$ & $93(15.74)$ \\
\hline In a relationship & $188(60.65)$ & $408(69.04)$ \\
\hline
\end{tabular}

Statistical methods. Assessment of the quality of health services (a dependent variable in the logistic regression model) was defined as a dichotomous variable which assumed the following two variants: a patient's satisfaction or dissatisfaction with the medical service received.

The final form of the logistic regression model with qualitative explanatory variables pointed to the determinants of primary health care patients' dissatisfaction with the quality of provided medical services. The model's goodness of fit was verified using the Hosmer-Lemeshow (HS) test. Furthermore, a Receiver Operating Characteristic (ROC) curve was constructed using the conformity of the indications of patients' satisfaction and dissatisfaction resulting from the model was evaluated against the actual indications. The area under the plot of the ROC curve was calculated, marked as AUC (Area Under Curve), which is a measure of the goodness of the model. The value of the statistic $\mathrm{HS}=7.9319$, with the value of $p=0.16003$, indicated a significant model fit of the logistic regression model. Based on the analysis of the area under the ROC curve, it can also be stated that the model fits the data well (the area is AUC $=0.834$ ) (Fig. 1, and is characterised by a good predictive ability resulting from the obtained sensitivity and specificity graphs for different levels of probability (Fig. 2).

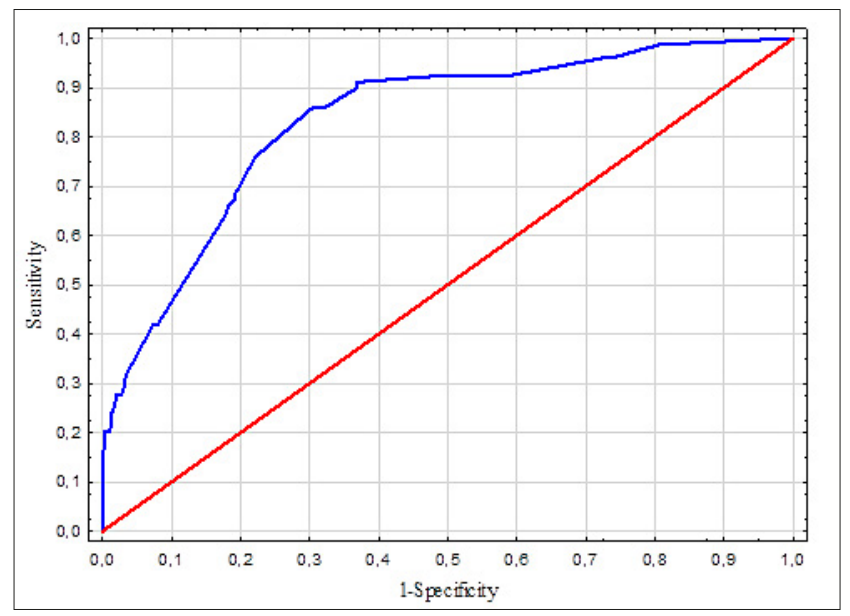

Figure 1. ROC curve graph

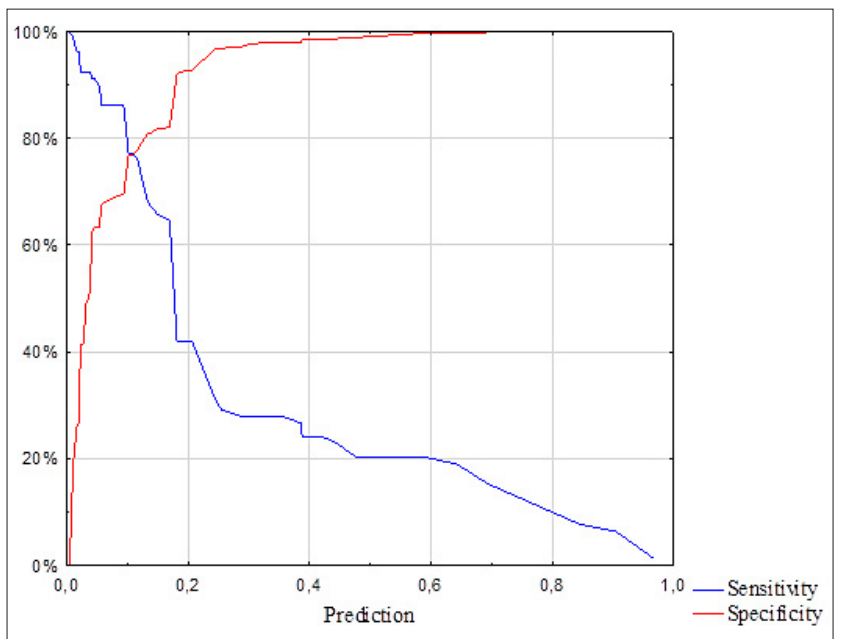

Figure 2. Sensitivity and specificity graph

A significance level of $\alpha=0.05$ was assumed in all statistical tests. Statistical analysis was performed using the STATISTICA ver. 13.1 advanced-analytics software. 


\section{RESULTS}

The construction of the model was preceded by a preliminary selection of predictors through an assessment of their quality using Cramér's $\mathrm{V}$ coefficient. At that stage, a number of predictors were discarded. The remaining predictors were included in the sequential construction of the logistic regression model. To achieve this, forward stepwise regression was used, and the significance of the difference between the subsequent models constructed was evaluated using Likelihood Ratio (LR) test. In the final step, another group of variables was discarde, as they proved to be insignificant (Tab. 2). The remaining variables, however, were included in the final version of the model (Tab. 2, Tab. 3). The predictors' statistical significance was verified using the Wald test.

Using logistic regression, the determinants which in the patients' opinions influence the dissatisfaction with medical services were established (Tab. 3).

Based on the estimated logistic regression, it can be stated that the chance of occurrence of a patient's dissatisfaction with a medical service is 8.7 times greater when a doctor is rude during a visit, compared to the situation when they are polite $(\mathrm{OR}=8.754 ; 95 \% \mathrm{Cl}: 3.625-21.140 ; \mathrm{p} 0.0001)$. Patients expect politeness and understanding from the doctor during a doctor's visit. The next determinant of dissatisfaction with the quality of services is the fact that a doctor does not admit patients in an emergency $(\mathrm{OR}=6.656 ; 95 \% \mathrm{Cl}$ : $3.062-14.469 ; \mathrm{p}=0.0001$, or when a GP sends the patient to a different $\mathrm{GP}(\mathrm{OR}=5.232 ; 95 \% \mathrm{Cl}: 2.598-10.535 ; \mathrm{p}=0.0001)$. In such a situation, the patient is often forced to use paid medical advice. The described situation happens more often in smaller primary health care institutions, where 1-2 GPs admit patients.

It is not only the attitude of the doctor, but also that of the remaining medical staff (nurses, obstetricians, nonmedical receptionists, and medical secretaries) that is an important matter influencing the patients' dissatisfaction with the quality of medical services. Lack of empathy and understandable communication between the patient and the remaining personnel working at primary health care institutions leads to the patient having negative experiences connected with the medical visit $(\mathrm{OR}=3.603$; 95\% Cl: $1.745-$ $7.439 ; \mathrm{p}=0.001$ ). Understanding the information about one's health condition is the basis of a treatment process, and this in turn determines the patients' proper actions and behaviours. Patients, when indicating their dissatisfaction with the quality of medical services, feel that the information regarding their health condition which they receive is not fully understandable to them $(\mathrm{OR}=4.170 ; 95 \% \mathrm{Cl}: 1.598$ 10.877; $\mathrm{p}=0.004)$.

Table 2. Statistically significant and insignificant predictors

\begin{tabular}{|c|c|c|}
\hline Predictors & Value of the Wald statistic & p-value \\
\hline \multicolumn{3}{|l|}{ Questions regarding the assessment of the quality of health care (section A) } \\
\hline The attitude of a doctor towards the patient - the doctor is rude & 23.263814 & 0.0000 \\
\hline Admission by a GP in case of emergency & 26.822824 & 0.0000 \\
\hline The attitude of the remaining personnel - the remaining personnel are rude & 12.003726 & 0.0005 \\
\hline $\begin{array}{l}\text { Understanding information about health - the information about the health condition is not understandable to the patient, } \\
\text { lack of full explanation of the health condition and the further process of treatment }\end{array}$ & 8.518855 & 0.0035 \\
\hline Availability of information about health - difficult access to information regarding the health condition (medical documentation) & 5.626592 & 0.0177 \\
\hline Type of visit & 2.178102 & 0.1399 \\
\hline Patient's consent to a given treatment & 0.001434 & 0.9698 \\
\hline The doctor taking the patient's monetary situation into account & 2.393783 & 0.3021 \\
\hline Assessment of house visits & 3.662625 & 0.1602 \\
\hline Waiting time for an appointment & 1.589945 & 0.2073 \\
\hline The ability to freely choose a doctor & 1.549588 & 0.2132 \\
\hline The manner in which a doctor welcomes the patient during a visit & 0.778833 & 0.6774 \\
\hline The course of a visit & 3.799975 & 0.1496 \\
\hline Waiting time for a visit & 0.160168 & 0.6890 \\
\hline Assessment of the inconvenience of waiting & 1.510083 & 0.2191 \\
\hline \multicolumn{3}{|l|}{ Questions on the use of e-Health tools (section B) } \\
\hline Clear identification of the patient in the system - lack of clear identification & 6.660334 & 0.0098 \\
\hline Transfer of the patient's medical data between healthcare institutions & 3.317207 & 0.3453 \\
\hline Standardised (uniform) medical data of a patient (for example test results, or orders) & 3.352502 & 0.3404 \\
\hline Access to medical data $24 \mathrm{~h}$ a day, seven days a week & 0.674903 & 0.8791 \\
\hline Security of the patient's sensitive data & 1.801599 & 0.6146 \\
\hline Utilising e-prescriptions & 3.949213 & 0.1388 \\
\hline Utilising e-referrals & 2.167056 & 0.3384 \\
\hline Utilising the Internet to exchange or obtain patients' medical data from other medical institutions & 3.394166 & 0.1832 \\
\hline
\end{tabular}


Table 3. Final predictors which were included in the (logistic regression) model.

\begin{tabular}{|c|c|c|c|c|}
\hline Variable - reference variant & Section & $\begin{array}{l}\text { Estimate of the logistic } \\
\text { regression parameter }\end{array}$ & OR $(95 \% \mathrm{Cl})$ & $\mathrm{p}$-value \\
\hline Constant term & & -5.199 & $0.006(0.002-0.014)$ & 0.000 \\
\hline A GP refuses admittance in an emergency & A & 1.895 & $6.656(3.062-14.469)$ & 0.000 \\
\hline A GP sends the patient to a different primary care physician & A & 1.655 & $5.232(2.598-10.535)$ & 0.000 \\
\hline $\begin{array}{l}\text { Understanding information about health - the information about the health condition is not } \\
\text { understandable to the patient, lack of full explanation of the health condition and the further } \\
\text { process of treatment }\end{array}$ & A & 1.428 & $4.170(1.598-10.877)$ & 0.004 \\
\hline Clear identification of the patient in the system - lack of clear identification & B & 1.126 & $3.084(1.311-7.255)$ & 0.010 \\
\hline $\begin{array}{l}\text { Availability of information about health - difficult access to information regarding the health } \\
\text { condition (medical documentation) }\end{array}$ & A & 0.677 & $1.968(1.125-3.443)$ & 0.018 \\
\hline
\end{tabular}

Another determinant is the lack of clear patient identification in the healthcare system $(\mathrm{OR}=3.084 ; 95 \% \mathrm{Cl}: 1.311-7.255 ; \mathrm{p}$ $=0.010$ ), which may lead to mistakes and a lack of complete medical documentation. Patients do not have full knowledge regarding primary health care institutions sharing medical documentation. This issue is regulated, amongst others, in the Act defining the principles of the functioning of primary health care and on Patients' Rights and on the Ombudsman for Patient Rights. This state causes the chance of dissatisfaction with the quality of medical services to increase almost two-fold, compared to the case in which patients have full information about and access to their medical documentation $(\mathrm{OR}=1.968 ; 95 \% \mathrm{Cl}: 1.125-3.443 ; \mathrm{p}=0.018)(\mathrm{Tab} .3)$.

\section{DISCUSSION}

A number of factors have impact on a patient's satisfaction with the quality of medical services at primary health care institutions. An examination of the literature showed a lack of publications concerning the determinants of patients' dissatisfaction with the quality of medical services at primary health care institutions in Poland.

An analysis of the research results proved that patients' dissatisfaction is primarily related to the attitude of a doctor and the remaining medical and non-medical personnel with regard to the patient, and to the lack of understanding of information related to the condition of the patient's health.

One of the goals of worldwide health politics is the strengthening of the role of primary medical care in the healthcare system, and especially concentrating on the improvement of the quality of medical services. Primary health care is the first element in a patient's contact with the healthcare system, and the medical services that are available as part of it should be continuous, coordinated, comprehensive and oriented towards the patient. It seems justified to search for and model system solutions in order that the healthcare system, and especially primary health care, can satisfy the needs of patients (and at the same time understand their changeability), and the expectations of the service recipients $[8,28]$.

According to the World Health Organisation, increasing a patient's satisfaction with medical services is the top priority for service providers. Patient satisfaction, in conjunction with other aspects of care, such as security, quality and clinical effectiveness, impact the overall assessment of the health services received by a patient [29]. The experiences of other countries show that communication is crucial in terms of improving a patient's safety, and the continuity of medical care. Patients, when using medical services, expect understandable information regarding the condition of their health, as well as commitment and understanding from the doctor's side. A patient's satisfaction is related to a specific assessment of the totality of a provided service [30]. The quality of the doctor-patient relationship and the interpersonal aspects of care have a meaningful impact on the trust that a patient has for the healthcare system [31-36]. At the same time, the patient's own commitment in the process of treatment allows for achieving the desired goal in the form of improving health [37]. Each patient requires an individual approach, which is why the process of treatment should be adjusted to a specific patient [38].

The patients' opinions regarding the provided medical services are used by EU countries to evaluate, control, accredit, and promote health care. The Health at a Glance Report indicates that Polish patients are the least considered carriers of rights in the healthcare system. Doctors devote the least of their time to them during a visit, and do not sufficiently introduce them into the decisions regarding the health condition and treatment. The average opinion of the quality of medical services provided by a GP or a health centre in Poland is one of the lowest in Europe [39].

The attitude and commitment of nurses also has an impact on the assessment of the quality of health services. Their professional competences and the manner of approaching a patient have an influence on the final recipient's, the patient's, perception of medical services [40-43].

Apart from the immaterial factors, system solutions have an impact on the negative assessment of the services provided by primary health care institutions. The authors investigated how e-Health solutions can determine the subjective opinions of the participants of the study. It turned out that patients primarily expect a clear identification in the healthcare system, whereas the remaining factors in e-Health proved to be irrelevant.

The functioning of primary health care is often limited by the lack of standardised data describing a patient in the system $[44,45]$.

e-Health solutions which are supposed to improve the functioning of health care in Poland are still being implemented and their effects can only be evaluated after their implementation. 
Building a general model which would allow for knowing the determinants which influence the patients' dissatisfaction with received medical services can contribute to understanding the expectations and needs of the patients. Such a model could then be used to improve the functioning of primary health care institutions. Constructing such a model should be preceded by, amongst others, recognition of the needs of primary health care patients [46].

\section{CONCLUSIONS}

It is essential for the functioning of medical facility to identify factors affecting dissatisfaction of patients with the received medical service. Moreover, the effectiveness of statistical methods (logistic regression model) in eHealth area should be underlined. The results may be useful for managers or executive staff to take corrective action which finally reduces the amount of weak points in the functioning of examined facilities.

The study allowed an understanding of the expectations of patients and showed that the most important factors to consumers are immaterial, whereas the components evaluate intuitive by authors as relevant in the model were initially identified as irrelevant, which proves that the satisfaction of patients is based on immaterial values. The weakest point of received medical service is the human factor - the attitude of medical and non-medical staff towards the patient who needs understanding, empathy and complete information. It is possible that patients have confidence in the quality of the service, which why, above all, they pay attention to they behavior of the health care professionals.

\section{Acknowledgements}

The project was financed in 2019-2022 in the amount of $11,999,000,00 \mathrm{zl}$ under the programme 'Regional Initiative of Excellence' of the Minister of Science and Higher Education (Project No. 024/RID/2018/19).

\section{REFERENCES}

1. Shizheng Du, Yuling Cao, Tong Zhou, Agus Setiawan, Myat Thandar, Virya Koy, Mohd Said Bin Nurumal, Hong Anh, Wipada Kunaviktikul, Yan $\mathrm{Hu}$. The knowledge, ability, and skills of primary health care providers in SEANERN countries a multi-national cross-sectional study. BMC Health Services Res. 2019; 19: 602.

2. Kalra S, Akanov ZA, Pleshkova AY. Thoughts, Words, Action: The Alma-Ata Declaration to Diabetes Care Transformation. Diabetes Ther. 2018; 9(3): 873-876.

3. White F. Primary health care and public health: foundations of universal health systems. Med Princ Pract. 2015; 24(2): 103-116.

4. Sanders D, Nandi S, Labonté R, Vance C, Van Damme W. From primary health care to universal health coverage-one step forward and two steps back. The Lancet 2019; 394(10199): 619-21.

5. Jamoulle M, Resnick M, Vander Stichele, Ittoo A, Cardillo E, Vanmeerbeek M. Analysis of definitions of general practice, family medicine, and primary health care: a terminological analysis. BJGP Open 2017; 1(3): bjgpopen17X101049.

6. Belén Espinosa-González A, Delaney BC, Marti J, Darzi A. The impact of governance in primary health care delivery: a systems thinking approach with a European panel. Health Res Policy Syst. 2019; 17: 65.

7. Rifkin SB. Alma Ata after 40 years: Primary Health Care and Health for All-from consensus to complexity. BMJ Global Health 2018; 3: e001188.

8. Kruk ME, Gage AD, Arsenault C, Jordan K, Leslie HH, Roder-DeWan S, et al. High-quality health systems in the Sustainable Development Goals era: time for a revolution. Lancet Glob HealTH 2018; 6(11): e1196-252.
9. Behzadifar M, Taheri Mirghaed M, Aryankhesal A. Primary Health Care: An Important Approach for Health Sector, Missed in Iran's Health System Evolution Plan. Iran J Public Health 2017; 46(9): 1307-1308.

10. Kruk ME, Nigenda G, Knaul FM. Redesigning Primary Care to Tackle the Global Epidemic of Noncommunicable Disease. Am J Public Health 2015; 105(3): 431-7.

11. Gauld R, Blank R, Burgers J, et al. The World Health Report 2008 Primary Healthcare: How Wide Is the Gap between Its Agenda and Implementation in 12 High-Income Health Systems? Health Policy 2012; 7(3): 38-58

12. Nylenna M, Bjertnaes Øyvind A, Saunes IS, Lindahl AK. What is Good Quality of Health Care? Professions and Professionalism 2015; 5(1): 1-16.

13. Mohammad Ali Abbasi-Moghaddam, Ehsan Zarei, Rafat Bagherzadeh, Hossein Dargahi, Pouria Farrokhi. Evaluation of service quality from patients' view point. BMC Health Services Res. 2019; 19: 170.

14. Ali Mohammad Mosadeghrad. Healthcare service quality: Towards a broad definition. Int J Health Care Quality Assurance 2013; 26(3): 203-19.

15. Allen-Duck A, Robinson JC, Stewart MW. Healthcare Quality: A Concept Analysis. Forum Nurs. 2017; 52 (4): 377-386.

16. Ssemugabo Ch, Nalinya S, Ali Halage A, Mubeezi Neebye R, Musoke D, Jors E. Doctors experiences on the quality of care for pesticide poisoning patients in hospitals in Kampala, Uganda: a qualitative exploration using donabedian's model. Health Services Res. 2020; 20: 30.

17. Alhassan RK, Duku SO, Janssens W, Nketiah-Amponsah E, Spieker $\mathrm{N}$, van Ostenberg $\mathrm{P}$, et al. Comparison of perceived and technical healthcare quality in primary health facilities: implications for a sustainable. National Health Insurance Scheme in Ghana. PLoS One 2015; 10(10): e0140109.

18. Chang Eun Kim, Joon-Shik Shin, Jinho Lee, Yoon Jae Lee, Me-riong Kim, Areum Choi, Ki Byung Park, Ho-Joo Lee, In-Hyuk Ha. Quality of medical service, patient satisfaction and loyalty with a focus on interpersonal-based medical service encounters and treatment effectiveness: a cross-sectional multicenter study of complementary and alternative medicine (CAM) hospitals. BMC Complement Altern Med. 2017; 17: 174.

19. Aggarwal A, Aeran A, Rathee M. Quality management in healthcare: The pivotal desideratum. J Oral Biol Craniofac Res. 2019; 9(2): 180-182.

20. Mandeep, Chitkara N, Goel S. Study to evaluate change of attitude toward acceptance of $\mathrm{NABH}$ guidelines: an intra-institutional experience. J Nat Accred Board Hosp Healthcare Providers. 2014; 1: $52-55$.

21. Ustawa o Podstawowej Opiece Zdrowotnej z dnia 27 października 2017 r. DzU 2019 poz. 357

22. Rolbina ES, Novikova EN, Sharafutdinova NS, Martynova OV, Akhmetshin RM. Analysis and Assessment of Quality of Medical Services in Conditions of Digital Transformation. In: Ashmarina S, Mesquita A, Vochozka M, editors. Digital Transformation of the Economy: Challenges, Trends and New Opportunities. Advances in Intelligent Systems and Computing, vol 908. Springer, Cham, 2020.

23. Ossebaard HC. eHealth and quality in health care: implementation time. Int J Quality Health Care 2016; 28(3): 415-419.

24. Melchiorre MG, Papa R, Rijken M, Ginneken E, Hujala A, Barbabella F. eHealth in integrated care programs for people with multi morbidity in Europe: Insights from the ICARE4EUproject. Health Policy 2018; 122(1): 53-63.

25. Reiners F, Sturm J, Bouw LJW, Wouters EJM. Sociodemographic Factors Influencing the Use of e-Health in People with Chronic Disease. Int J Environ Res Public Health 2019; 16(4): 645.

26. Apolinário-Hagen J, Menzel M, Hennemann S, Salewski CH. Acceptance of Mobile Health Apps for Disease Management Among People With Multiple Sclerosis: Web-Based Survey Study JMIR Formativ Res. 2018; 2(2): e11977.

27. Duplaga M. A cross-sectional study assessing determinants of the attitude to the introduction of eHealth services among patients suffering from chronic conditions. BMC Med Inform Decis Mak. 2015; 19: 15-33.

28. Bitton A, Ratcliffe HL, Veillard JH, Kress DH, Barkley S, Kimball M, et al. Primary health care as a foundation for strengthening health systems in low- and middle-income countries. J Gen Intern Med. 2017; 32(5): 566-71. doi: 10.1007/s11606-016-3898-5

29. Van der Zwart J, van der Voordt T. Pre-Occupancy Evaluation of Patient Satisfaction in Hospitals. Health Environ Res Design J. 2015; 9(1): 110-124.

30. Astuti HJ, Nagase K. Patient loyalty to healthcare organization: relationship marketing and satisfaction. Int J Manage Marketing Res. 2014; 7(2): 39-56. 
31. Khan MM, Khan AH. Impact of service quality on patient's trust; A case of health-care in Pakistan. J Quality Technol Manage. 2014; 10(1): 35-57.

32. Zielińska-Więczkowska H. Empatia wśród przedstawicieli zawodów medycznych - korzyści a ryzyko wypalenia zawodowego. Med Rodz. 2016; 4: 255-260.

33. Hernan AL, Giles SJ, Fuller J, et al. Patient and carer identified factors which contribute to safety incidents in primary care: a qualitative study. BMJ Qual Saf. 2015; 24: 583-93.

34. Ricci-Cabello I, Marsden KS, Avery AJ, et al. Patients' evaluations of patient safety in English general practices: a cross-sectional study. $\mathrm{Br}$ J Gen Pract. 2017; 67: e474-82.

35. Błachnio A, Buliński L. Wellbeing and older adults in primary health care in Poland. Ann Agric Environ Med. 2019; 26(1): 55-61.

36. Makara-Studzińska M, Wontorczyk A, Izydorczyk B. Stress and occupational burnout in a population of Polish doctors - Organizationalprofessional and non-professional-social predictors. Ann Agric Environ Med. doi: 10.26444/aaem/110846

37. Jha D, Frye AK, Schlimgen J. Evaluating variables of patient experience and the correlation with design. Patient Experience J. 2017; 4(1):33-45.

38. Mehta SJ. Patient satisfaction reporting and its implications for patient care. AMA J Ethics 2015; 17(7): 616-621.

39. Report Health at a Glance: Europe 2018: State of Health in the EU Cycle, OECD Publishing, Paris. https://doi.org/10.1787/health_glance_eur2018-en
40. Al Shammari M, Al Habib S, Al Shubrami D, Al Rashidi M. Impact of hospital' accreditation on patient safety in Hail city, Saudi Arabia: nurses' perspective. J Nurs Health Sci. 2015; 4(1): 51-55.

41. Yildiz A, Kaya S. Perception of nurses on the impact of the accreditation on quality of healthcare. Clinical Governance: An International J. 2014; 19 (2): 69-82.

42. Smoleń E, Ksykiewicz-Dorota A. Profesjonalizm pielęgniarek jako element oceny satysfakcji rodziców/opiekunów dzieci z opieki pielęgniarskiej. Med Pr. 2015; 66(4): 549-556.

43. Grochowska A, Kubik B, Romanowska U, Lebica M. Burnout among nurses. Medical Studies/Studia Medyczne. 2018; 34(3): 189-195. doi: $10.5114 / \mathrm{ms} .2018 .78681$

44. Ratcliffe HL, Schwarz D, Hirschhorn LR, Cejas C, Diallo A, Elorrio EG, Fifield J, Gashumba D, Hartshorn L, Leydon N, Mohamed M, Nakamura Y, Ndiaye Y, Novignon J, Ofosu A, Roder-DeWan S, Rwiyereka A, Secci F, Veillard JH, Bitton A. PHC Progression Model: a novel mixedmethods tool for measuring primary health care system capacity. BMJ Glob Health. 2019; 4(5): e001822. doi: 10.1136/bmjgh-2019-001822

45. Ware P, Bartlett SJ, Pare G, et al. Using eHealth technologies: interests, preferences, and concerns of older adults. Interact J Med Res. 2017;6:e3 46. Strzelecka A, Stachura M, Wójcik T, Pacian AB, Kulik T, Pacian J, Kaczoruk M, Galińska EM, Kawiak-Jawor E, Nowak-Starz G. Using affinity analysis in diagnosing the needs of patients as regards e-Health. Ann Agric Environ Med. doi: 10.26444/aaem/123872 